\title{
Transcutaneous carbon dioxide monitoring during procedures requiring sedation and future implications for patients at risk of respiratory depression
}

\author{
Annabel Lim, MD, MA (Cantab) (1) • Megan Allen, BMBS (Hons), BSc (Biomed), MClinEpi, FANZCA • \\ Siak Lee, MBBS, BMedSci (Hons) • Bernhard Riedel, MBChB, FCA, FANZCA, FAHA, FASE, MMed, \\ MBA, PhD
}

Received: 31 January 2018/Revised: 24 March 2018/Accepted: 9 April 2018/Published online: 19 April 2018

(C) Canadian Anesthesiologists' Society 2018

\section{To the Editor,}

Patients are at risk of respiratory depression and acute hypercapnia during sedation and recovery from anesthesia. Desaturation on pulse oximetry is a late sign and can be significantly masked by administration of supplemental $\mathrm{O}_{2}{ }^{1}$ Global standards vary on the use of end-tidal or expired $\mathrm{CO}_{2}$ measurement during sedation; ${ }^{2,3}$ however, traditional $\mathrm{CO}_{2}$ measurement can be technically challenging depending on the airway management technique and the procedure itself in the case of the shared airway. Transcutaneous $\mathrm{CO}_{2}$ partial pressure $(\mathrm{tcpCO})$ is a non-invasive surrogate measure that correlates well with $\mathrm{PaCO}_{2}$ on arterial blood gas analysis. ${ }^{4, \mathrm{~A}}$ Transcutaneous $\mathrm{CO}_{2}$ partial pressure offers a more accurate measure of $\mathrm{CO}_{2}$ compared with capnography with nasal prongs because of the open circuit arrangement of the latter. We aimed to evaluate the change in $\mathrm{tcpCO}_{2}$ during sedation for gastrointestinal endoscopy.

Following ethics approval (HREC LNR/17/PMCC/97), we conducted a prospective observational cohort study using tcpCO $\mathrm{O}_{2}$ monitoring (Radiometer TCM5, Denmark) in addition to standard Australian and New Zealand College

A. Lim, MD, MA (Cantab) ( $\square) \cdot$ M. Allen, BMBS (Hons), BSc (Biomed), MClinEpi, FANZCA · S. Lee, MBBS, BMedSci

(Hons) · B. Riedel, MBChB, FCA, FANZCA,

FAHA, FASE, MMed, MBA, PhD

Department of Cancer Anaesthesia, Perioperative and Pain

Medicine, Peter MacCallum Cancer Centre,

Melbourne, Australia

e-mail: annabel.lim@petermac.org; annabel.lim8@gmail.com

M. Allen, BMBS (Hons), BSc (Biomed), MClinEpi, FANZCA .

B. Riedel, MBChB, FCA, FANZCA, FAHA,

FASE, MMed, MBA, PhD

University of Melbourne, Melbourne, Australia of Anaesthetists' monitoring for patients undergoing gastrointestinal endoscopy during a five-week study period. Sedation and airway management (nasal prongs [ $n=15]$, Hudson mask [ $n=29]$, high-flow humidified nasal oxygen $[n=12$, flow 20-45 L]) were at the discretion of the treating anesthetist. Research personnel applied tcpCO $\mathrm{CO}_{2}$ monitoring and recorded data, including: demographics, anesthetic management, baseline and peak tcpCO ${ }_{2}$, duration of sedation, and occurrence and time to occurrence of pre-determined respiratory endpoints: hypercapnia $\left(\mathrm{tcpCO}_{2}>45 \mathrm{mmHg}\right), \quad$ hypoventilation (respiratory rate $<10$ breaths. $\mathrm{min}^{-1}$ ), and hypoxia $\left(\mathrm{SpO}_{2}<92 \%\right)$.

A total of 56 patients were investigated. Procedures included colonoscopy $(n=31 ; 55 \%)$, combined colonoscopy and gastroscopy $(n=13 ; 23 \%)$, gastroscopy $(n=7 ; 13 \%)$, and flexible sigmoidoscopy $(n=5 ; 9 \%)$. All patients received propofol; the majority received adjunct opioid (fentanyl or alfentanil; $n=42 ; 75 \%$ ) and three patients also received midazolam. The mean duration of sedation was 27.6 (standard deviation 10.3) min.

We confirmed that tcpCO $\mathrm{CO}_{2}$ is a successful method of non-invasively monitoring the response to dynamic respiratory changes associated with sedation. Nevertheless, only one of the six patients with hypoxia presented with hypercapnia, supporting findings that hypoxia is a separate phenomenon and so $\operatorname{tcpCO}_{2}$ is unlikely to be a reliable monitor for rapid detection of intra-procedure hypoxia and adverse respiratory events. ${ }^{1}$

While over half of our cohort became hypercapnic, this is unlikely to be clinically significant at the levels found during our study. Not surprisingly, we found a higher peak

\footnotetext{
A Thomsen $A M$. The tcpCO ${ }_{2}$ Handbook. Denmark: Radiometer Medical ApS, 2012.
} 
Table Oxygenation and ventilation during endoscopy

\begin{tabular}{|c|c|c|c|}
\hline Parameter & Whole cohort $(n=56)$ & Received opioids $(n=42)$ & No opioids $(n=14)$ \\
\hline Baseline tcpCO ${ }_{2}[$ mean (SD)] & $34.9(4.5)$ & $35.0(4.8)$ & $34.6(3.5)$ \\
\hline Peak tcpCO $2[$ mean (SD)] & $47(6.3)$ & $48(6.5)$ & $44(4.7)$ \\
\hline Change in $\mathrm{tcpCO}_{2}[$ mean (SD)] & $12.1(5.4)$ & $13.1(5.3)$ & $9.2(4.6)$ \\
\hline Hypercapnia (tcpCO ${ }_{2}>45 \mathrm{mmHg}$ ); [number $(\%)$ ] & $30(54 \%)$ & & \\
\hline Time to hypercapnia (min) (median [IQR]) & $5.8[4.1-7.5]$ & & \\
\hline Hypoventilation $(\mathrm{RR}<10)$ [number $(\%)$ ] & $18(32 \%)$ & & \\
\hline Time to hypoventilation (min) (median [IQR]) & $3.5[2.8-8.7]$ & & \\
\hline Hypoxia $\left(\mathrm{SpO}_{2}<92 \%\right)$ [number $\left.(\%)\right]$ & $6(11 \%)$ & & \\
\hline Time to hypoxia (min) (median [IQR]) & $4.1[3.3-5.1]$ & & \\
\hline
\end{tabular}

$\mathrm{IQR}=$ interquartile range; $\mathrm{RR}=$ respiratory rate; $\mathrm{SD}=$ standard deviation; $\mathrm{tcpCO} \mathrm{CO}_{2}=$ transcutaneous $\mathrm{CO}_{2}$ partial pressure

tcpCO $\mathrm{CO}_{2}$ in patients who had received opioids. Future areas for investigation include the application of $\mathrm{tcpCO}_{2}$ monitoring in the postanesthesia care unit and in specific target populations, e.g., those with PCAs, intrathecal morphine, or in cases such as robotic or laparoscopic surgery, where systemic absorption of $\mathrm{CO}_{2}$ may continue postoperatively. ${ }^{5}$ Overall, we believe that $\mathrm{tcpCO}_{2}$ monitoring has the potential to be a useful tool in addition to expired $\mathrm{CO}_{2}$ monitoring or in situations where traditional monitoring cannot be readily utilized.

Conflicts of interest None declared.

Editorial responsibility This submission was handled by Dr. Gregory L. Bryson, Deputy Editor-in-Chief, Canadian Journal of Anesthesia.

\section{References}

1. Ayas N, Bergstrom LR, Schwab TR, Narr BJ. Unrecognized severe postoperative hypercapnia: a case of apneic oxygenation. Mayo Clin Proc 1998; 73: 51-4.

2. Dobson G, Wong M, Chow L, et al. Guidelines to the practice of anesthesia - revised edition 2017. Can J Anesth 2017; 64: 65-91.

3. Australian and New Zealand College of Anaesthetists. PS09: Guidelines on Sedation and/or Analgesia for Diagnostic and Interventional Medical, Dental or Surgical Procedures. Melbourne: Australian and New Zealand College of Anaesthetists (ANZCA); 2014 .

4. Heuss LT, Chhajed PN, Schnieper P, Hirt T, Beglinger C. Combined pulse oximetry/cutaneous carbon dioxide tension monitoring during colonoscopies. Digestion 2004; 70: 152-8.

5. Lee YC, Park JH. Postoperative delayed hypercapnia and respiratory failure after robot-assisted lower anterior resection. Korean J Anesthesiol 2013; 65(6 Suppl): S115-6. 